\title{
A construção de Cenários como um recurso de apoio a tomada de decisão nos pro- cessos de projetos audiovisuais
}

\author{
PEREIRA, Clarissa; Mestre em Design; Universidade do Vale dos Sinos \\ pereira.g.clarissa@gmail.com \\ SCALETSKY, Celso; Doutor em Design; Universidade do Vale dos Sinos \\ celsos@unisinos.br
}

Palavras-Chave: Tomada de Decisão, Design, Projeto por Cenários, Indústria Audiovisual.

\begin{abstract}
Resumo: Estudos voltados ao tema de construção de cenários de design têm sugerido que a prática é capaz de oferecer auxílio às tomadas de decisão que envolvem o processo de projeto. Este artigo propõe estabelecer uma reflexão em torno da cenarística como um recurso de apoio ao processo decisório de outras indústrias além do design, neste caso da indústria audiovisual. As articulações são fundamentadas no conceito de Nigel Cross sobre o "Design Ways of Knowing" e na visão de "Projeto por Cenários" apresentada por Paulo Reyes. Desta reflexão podem surgir recursos conceituais que subsidiem os processos projetuais não só do design mas também de outras indústrias e avanços nos estudos relacionados a construção de cenários.
\end{abstract}

\section{Introdução}

A economia criativa pode ser entendida como todas aquelas atividades que têm como princípio a criatividade, a habilidade, o talento individual e que potencializam a criação de emprego e de riqueza através da exploração da propriedade intelectual (UNPD, 2013). Foi o britânico John Howkinks (2013) quem cunhou o termo e estabeleceu fronteiras à estas atividades, delimitando a economia criativa a treze indústrias: artesanato, arquitetura, artes cênicas, design, audiovisual, editorial, moda, música, publicidade, software, games, televisão e rádio. Este estudo, interessa-se por discutir a relação entre duas indústrias particulares desta nova economia, o design e o audiovisual. O objetivo é construir uma reflexão sobre como as estratégias de design podem auxiliar no processo decisório dos projetos audiovisuais.

O mercado audiovisual é o espaço no qual ocorre a produção e comercialização de conteúdos produzidos para serem exibidos nas salas de cinema, TV paga, TV aberta, vídeos sob demanda e mídias móveis. Esta indústria tem apresentado um crescimento forte e sustentado, tornando-se um segmento estratégico para a economia do país e uma potência ascendente na geração de renda, de empregos e de transformações sociais e culturais (ANCINE, 2015). Um dos desafios para que o ramo mantenha esse crescimento é conciliar o raciocínio objetivo da indústria com o pensamento subjetivo da criação. Isto porque, o audiovisual atua predominantemente por meio de projetos e - igualmente aos demais setores que compõe a economia criativa - opera com aspectos subjetivos e cognitivos do ato criativo que incorporam obstáculos e complexidades à condução do processo projetual.

Esta dificuldade transparece especialmente em momentos de tomada de decisão. O centro de pesquisas NESTA - Organização britânica que administra o fundo nacional para a ciência, tecnologia e artes do Reino Unido, identificou que mais de um terço das empresas deste campo tinham problemas em deliberar escolhas para os seus projetos devido a estes aspectos. 
Uma opção de apoio que tem sido comumente empregada é a utilização de ferramentas provenientes de campos habituados a trabalhar com dados concretos e com uma linha de raciocínio lógico como a administração e a engenharia. A simples adaptação destes instrumentos tem encontrado limitações e se mostrado até mesmo inadequada para a realização de determinadas escolhas no âmbito criativo.

O design é um campo do conhecimento que vem investigando sobre como as decisões são realizadas durante o processo de projeto e, possivelmente, pode constituir um caminho para auxiliar a problemática do audiovisual. Conforme Kees Dorst (2006), um projeto é criado a partir de uma sequência de decisões que estão interconectadas e o próprio designer, durante a prática profissional, é um ator de tomada de decisão.

Na visão de Lockwood (2010), isto se deve a sua aptidão em equilibrar o pensamento analítico com o pensamento exploratório. Em outras palavras, o design trabalha com a dimensão subjetiva e cognitiva sem subestimar a extensão racional e reflexiva. Para Cross (2006) o campo caracteriza-se pela sua maneira de encontrar e processar conhecimentos que lhe são válidos. O autor denomina essa forma singular de raciocinar como "Design Ways of Knowing", que contempla uma cultura própria para conduzir processos de projetos e tomar decisões a respeito do problema.

Dentre as estratégias que o design possui para lidar com a complexidade da tomada de decisão, este estudo dedica-se a trabalhar o recurso de construção de cenários. Em particular, o conceito proposto por Reyes (2015) designado de "Projeto por Cenários", no qual pensa-se no futuro como mundos possíveis e projetam-se artefatos e condições para que determinada cena ocorra ou seja evitada.

Ao mesmo tempo em que observa-se que a indústria audiovisual possui dificuldades para tomar decisões e carece de instrumentos que a auxilie, o design possui recursos, como os cenários, que o habilita a lidar eficientemente com a ação decisória em meio a processos de projetos criativos.

A partir destes pressupostos, o presente artigo propõe estabelecer uma reflexão a respeito do projeto por cenários como um recurso potencial de apoio ao processo decisório nos projetos audiovisuais. Para compreender como a cenarística poderia auxiliar, buscou-se explorar os conceitos sobre tomada de decisão e processo decisório, analisar a forma de raciocinar do design proposta por Nigel Cross (2006) e articular a aplicabilidade e capacidade de auxílio da construção de cenários de design.

\section{A Tomada de Decisão e o Processo Decisório}

As atividades desenvolvidas em um projeto são, em sua essência, ações de tomada de decisão. No entender de Henry Mitznberg (1976) a decisão é um comprometimento para ação, um conjunto de iniciativas que inicia com a identificação de um problema ou uma oportunidade e que se encerra com uma indicação específica para ação. Estas decisões abrangem desde escolhas triviais até aquelas capazes de impactar o andamento de um projeto. Este segundo tipo de decisão é designada como estratégica e é pela qual este estudo se debruça.

Ao segmentar as decisões em programadas e não programadas/estratégicas, Simon (1972) aprofunda e esclarece suas diferenças conforme ilustra a tabela 1. 


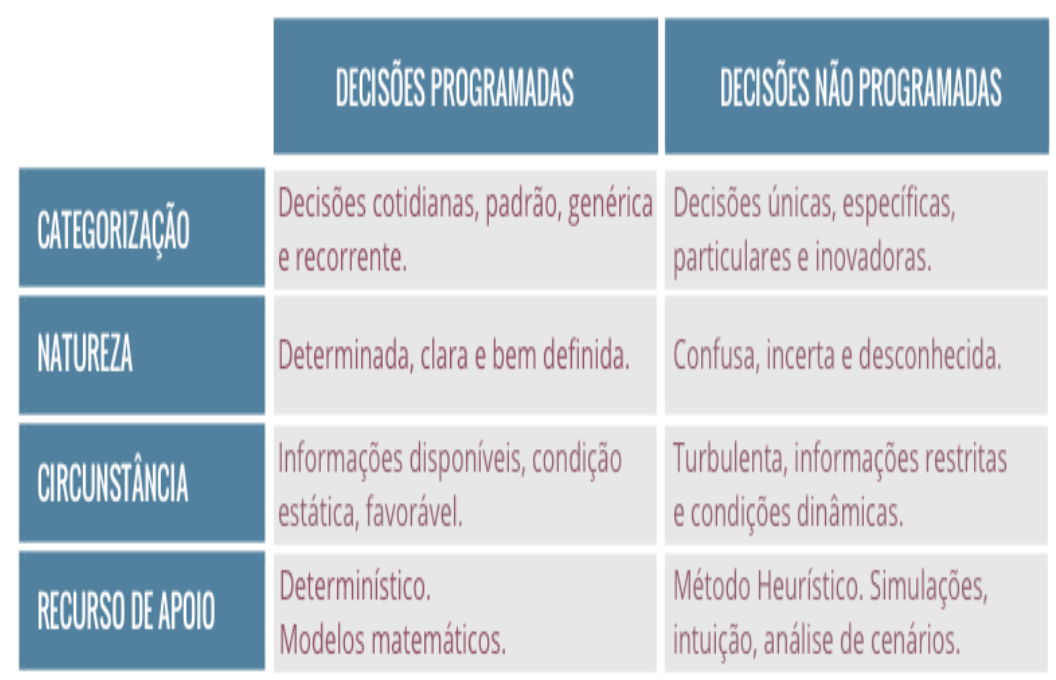

Fonte: A Autora (2016), inspirado em Simon (1972) e Abramczuk (2009).

As decisões programadas seguem um determinado parâmetro e pertencem a um "acervo" de soluções. Resolvem problemas que já foram enfrentados anteriormente e entregam os mesmos resultados se aplicados em situações similares.

As não programadas ou estratégicas são idealizadas individualmente com o objetivo de resolver problemas que as soluções padronizadas não conseguem. São propostas criadas para situações inéditas e permitem soluções diferenciadas. Bazerman (2004) salienta que decisões estratégicas são aquelas realizadas de maneira particular, pois consideram condições específicas de determinadas circunstâncias no intuito de atingir macro objetivos e influenciar um curso de atividade.

Decisões de natureza confusa e indefinida como as não programadas, carregam um volume considerável de riscos e incertezas, os quais demandam um processo estruturado que contemple desde uma delicada análise, a um diagnóstico e compreensão do problema que irá resultar posteriormente na deliberação de uma escolha.

Simon (1987) já havia ressaltado que a tomada de decisão não ocorre de maneira isolada e sim, pertence a um processo decisório. Este processo é complexo, pois exige a consideração de diversos elementos interdependentes e normalmente a decisão deve atender a múltiplos objetivos. Além disso, dificilmente seus impactos podem ser correntemente identificados devido a enorme influência de fatores externos como oportunidades de mercado, experiência do tomador de decisão e tempo disponível para decidir (ABRAMCZUCK, 2009).

Uma forma de compreender o processo decisório é vê-lo como uma sequência de estágios decompostos que convergem para uma solução. Estes passos permitem a definição do problema, a avaliação das possíveis soluções e a deliberação de uma alternativa. É com este procedimento que são medidas as

\section{UFPEL}




\section{SULDESIGN CIENTÍFICO 2017}

VIII Suldesign - encontro sul-americano

opções consideradas adequadas para atingir fins desejados. Portanto, o processo decisório pode ser entendido como um conjunto de etapas, ações e fatores que tem início com um estímulo para ação e se finaliza com uma determinação para ação (BRAGA, 1988). De acordo com o filósofo estadunidense John Dewey (1953, apud Abramczuk, 2009) o processo é constituído pelos seguintes estágios:

Figura 1 - Estágios do processo decisório

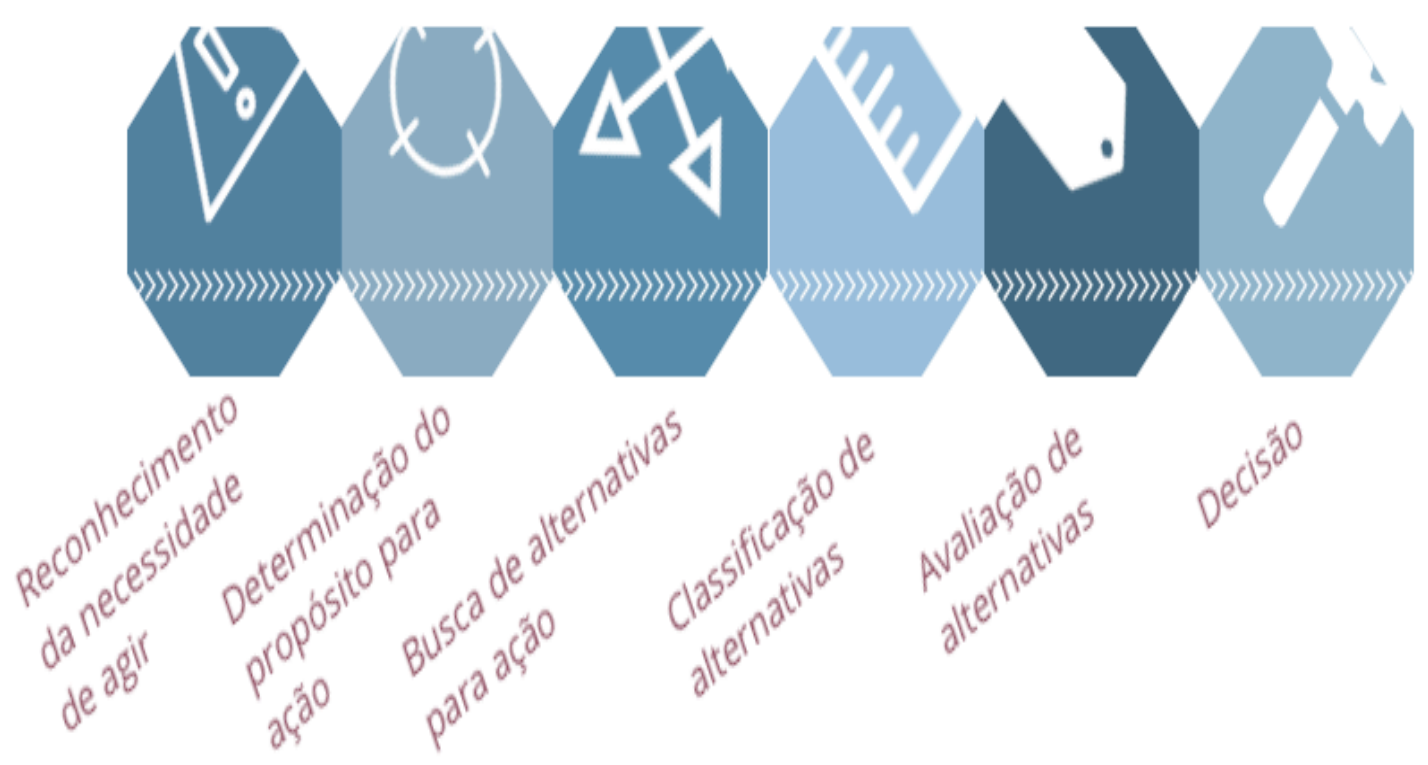

Fonte: A Autora (2016) inspirado em Abramczuk (2009).

Cyert e March (1993) explicam que todos estes estágios são guiados por quatro preceitos: resolução de conflitos, evitar incertezas, pesquisa do problema e aprendizagem organizacional. A partir do que foi mencionado pelos autores acima, desenvolveu-se uma tabela com enfoque nos setores investigados por este trabalho e nos autores que teorizam sobre eles. Supõem-se que os preceitos que guiam o processo decisório no audiovisual e no design tangenciem as seguintes considerações demonstradas na tabela 3 : 
Tabela 3 - Preceitos do processo decisório

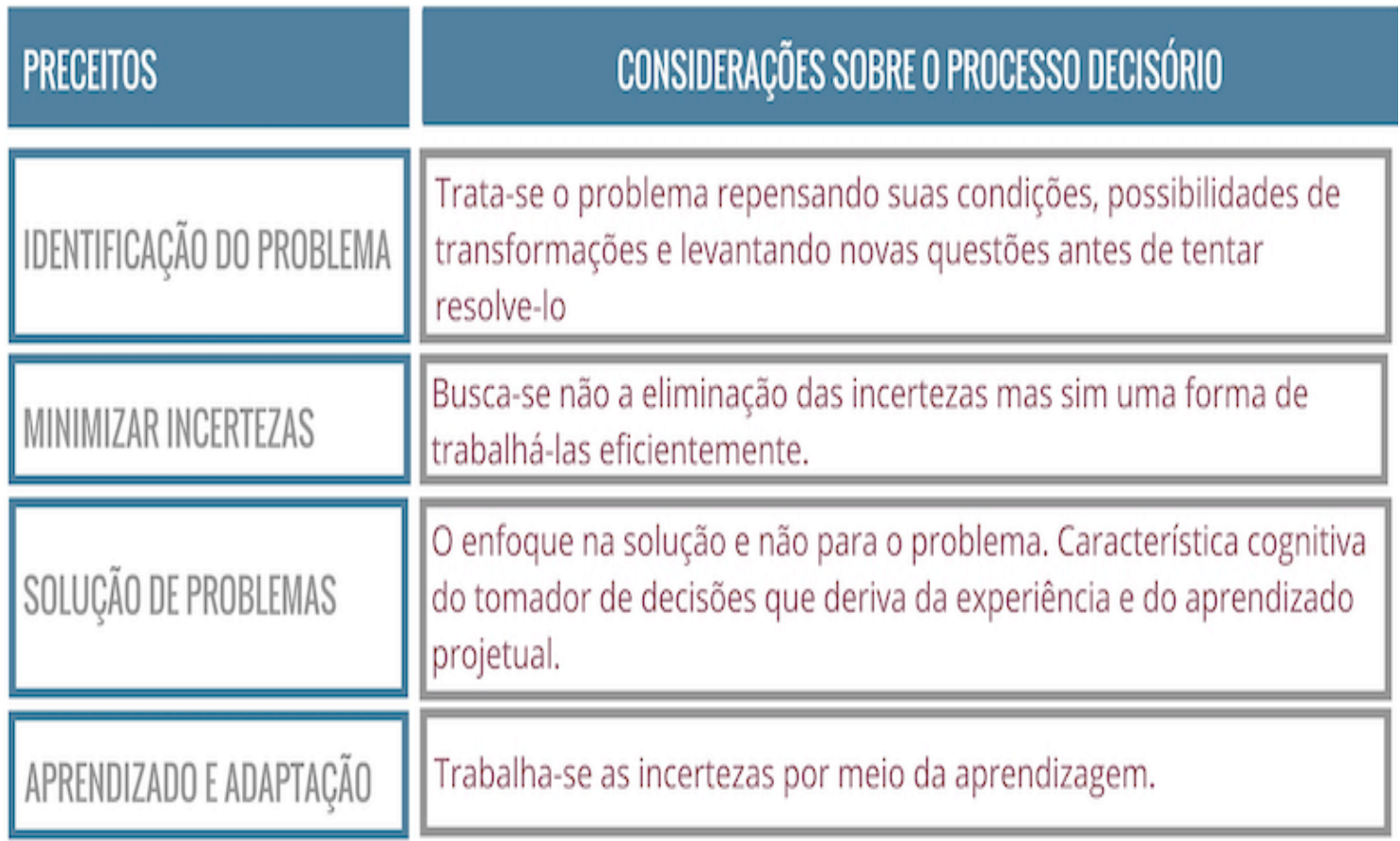

Fonte: A autora (2016) inspirado em Cross (2006) e Meroni (2008).

A concepção de que um processo de escolha deve obedecer a uma ordenação única de estágios consecutivos é criticada por alguns estudiosos (ABRAMCZUK, 2009). Alega-se que uma forma mais adequada de guiar o processo deveria criar facilidades para que as reflexões e ações de cada estágio possam ocorrer em diferentes momentos e em diferentes ocasiões. Esta formulação está muito associada à maneira de raciocinar do design que será abordada no tópico seguinte.

\section{Design Ways Of Knowing}

De acordo com Friedman (2003), design refere-se a processo. É sempre orientado por um objetivo como a solução de um problema, a satisfação de uma necessidade, a melhoria de situações ou a criação de algo novo. Ressalta-se que perceber o design apenas no domínio da resolução de problemas é restritivo. Ele deve ser entendido como uma prática exploratória que articula racionalidade e intuição, dois processos cognitivos complementares entre si. O design não é um conjunto de habilidades técnicas, mas um processo que envolve uma maneira específica de raciocinar e construir conhecimentos (Cross, 2006). O autor afirma que essa maneira de raciocinar consiste no pensamento não linear, na habilidade de resolução de problemas complexos e abertos, e na sustentação do desenvolvimento cognitivo. O pensamento não linear, considera a indeterminação substancial que o problema carrega e o fato de que não há um estado definitivo ou limite para a sua exploração (BUCHANAN, 1992). Esta forma de raciocinar não exige uma definição estruturada e clara do problema para buscar sua solução. As ações realizadas em diferentes estágios projetuais, 
influenciam o desenvolvimento do resultado como um todo, em uma co-evolução do problema e da sua resolução (DORST, 2003). Esta co-evolução pode ser associada a característica aberta dos problemas de design. Não existe uma única resposta, assim como não existem informações suficientes para gozar de alguma certeza. O designer interpreta, cria e sugere possíveis caminhos que só poderão ser definidos durante o processo de projeto. O termo evolução, neste contexto, pode ser associado a noção de que as ideias ou decisões mais satisfatórias "sobreviverão".

Assim, compreende-se que o problema não é completamente definido até que as soluções comecem a ser projetadas. Para trabalhar neste panorama incerto, o designer elabora hipóteses, simula situações, testa propostas e a partir das considerações observadas, surgirão alternativas para a deliberação do problema, (SIMON 1987).

Este contexto confuso e indefinido remete ao que pedagogo americano Donald Schön (2000) chama de "elemento surpresa". Existem situações que se apresentam de forma inesperada e com componentes desconhecidos. Estas circunstâncias são únicas e não podem ser solucionadas a partir de técnicas e teorias existentes. Assim, promove-se um processo de geração de conhecimento, pois como alternativa criam-se novos saberes na busca de resolver o problema e consequentemente uma reflexão sobre os conhecimentos criados.

Para o autor isso configura a reflexão-na-ação, o processo de gerar conhecimentos enquanto se realiza algo, e a reflexão sobre o que está sendo realizado conduz, frequentemente, a outros saberes e novas ações. Como se o pensamento moldasse o que está sendo feito enquanto está sendo feito.

Sob outra perspectiva, Kahneman (2003) afirma que diante de situações em que o designer não possui informações suficientes para tomar uma decisão segura ou que esteja lidando com uma série de indefinições, seu cérebro ativa processos heurísticos. É através das heurísticas que a intuição atua no processo decisório, criando julgamentos que surgem de forma rápida, associativa, emocional baseados em impressões e experiências passadas do profissional.

Percebe-se que ao tomar decisões em ambientes confusos e sem informações suficientes o tomador de decisões é estimulado a pensar no futuro, pois tende-se a criar simulações em cima das alternativas de escolha. Tenta-se vislumbrar quais seriam os resultados se a decisão tomada hoje fosse " $x$ " ou " $y$ ". Essa geração de hipóteses e análise de alternativas auxilia em uma tomada de decisão mais consistente e embasada. Nesse sentido o próximo tópico deste artigo aborda o recurso de construção de cenários como uma estratégia de apoio para a deliberação de escolhas.

\section{Projeto por Cenários}

Os cenários orientados pelo design buscam através da criação de um mundo futuro nortear as ações e decisões que são assumidas no presente com o objetivo de alcançar futuros desejáveis. Seu foco reside nas questões estratégicas que envolvem escolhas de riscos que carecem de informações auxiliares. Os cenários não devem ser tratados como instrumentos de previsão nem como histórias narrativas e sim, como uma estratégia ou forma de pensar o projeto.- 
A projetação destes mundos oportuniza que diferentes profissionais pensem coletivamente a respeito do "amanhã". As discussões revelam inúmeras reflexões e a conjugação destas diferentes perspectivas não só gera novos aprendizados que ampliam o campo mental dos atores envolvidos, mas também viabiliza uma linguagem em comum entre os participantes.

Celaschi (2007) escreve que o cenário representa na verdade uma plataforma de reflexão, compartilhamento e administração de horizontes. Um dos seus objetivos é arquitetar uma visão compartilhada e para tanto, põe-se em dúvida antigos aprendizados, deslocando visões estabelecidas e desafiando o modelo mental vigente. Deserti (2007) argumenta que o recurso é especialmente interessante pela sua capacidade de fornecer estímulos para guiar a tomada de decisão no presente.

Grande parte deste auxílio provém da representação visual que constitui a prática. Ela garante uma fácil leitura do contexto, seus elementos e do encadeamento para a decisão. Ao oferecer suporte a interpretação o cenário garante um processo de escolha mais edificado, consistente e transparente (REYES, 2015)

A ênfase do "Projeto por Cenários" aponta que a construção desse mundo futuro passa a ser um meio e não um fim em si mesmo. Em outras palavras, ao projetar por cenários o objetivo não reside somente em construir possíveis futuros e sim, durante essa construção, encontrar meios de aprimorar o projeto como uma ação aberta e não restritiva (REYES, 2015).

Acredita-se que projetar por cenários seja o conceito mais apropriado para se analisar a influência da cenarística na tomada de decisão. Observa-se que o cenário de design não só vem ao encontro das necessidades da indústria audiovisual em relação as suas dificuldades no processo decisório, mas também lida de maneira construtiva e produtiva com os aspectos objetivos e subjetivos do pensamento que são justamente os obstáculos da tomada de decisão no ramo audiovisual.

\section{Considerações Finais}

No presente artigo buscou-se estabelecer uma reflexão sobre de que maneira a construção de cenário pode auxiliar o processo decisório nos projetos audiovisuais, com o propósito de discutir sobre a possível aplicabilidade deste recurso em outra esfera além do design. A partir das lacunas apresentadas pela indústria audiovisual, foi possível traçar uma relação entre as suas limitações durante a tomada de decisão e o apoio que este recurso específico do design pode propor.

Para Reyes (2015) a cenarística fornece diferentes meios para serem construídas as bases de informações que irão apoiar a tomada de decisão. A prática organiza e torna compreensível dados do contexto, guiando e inspirando o desenvolvimento de um projeto. Muitas vezes cenários não fornecem soluções, apenas apoiam ou estimulam a reflexão sobre possíveis caminhos. Estes caminhos poderão auxiliar nos diferentes tipos de tomada de decisão. Conciliar o raciocínio lógico e objetivo da indústria com a reflexão subjetiva da criação - que encontra-se como um dos desafios da indústria audiovisual - é um aspecto positivo da prática, pois o cenário articula o pensamento criativo, sistêmico e divergente para descrever uma lógica narrativa sobre um possível "amanhã".

Ao projetar por cenários, mantem-se o projeto em constante aprimoramento enquanto perdurar a 


\section{SULDESIGN CIENTÍFICO 2017}

VIII Suldesign - encontro sul-americano

prática. Os exercícios irão gerar novos conhecimentos que conduzirão a reflexões, que por sua vez implicarão nas ações posteriores. $O$ procedimento pode ter ciclos ou manter a característica não linear do design, no entanto o projeto não permanece o mesmo. A cada evolução melhora-se e alcança-se uma maior aproximação da situação futura desejada. Assim a evolução dos estágios que constituem o processo decisório é gradual e construtiva.

Celaschi (2007), ao afirmar que o cenário é de fato um espaço reflexivo, indica que atividade condutora dos cenários é o diálogo e a riqueza que existe na troca de conhecimentos entre os envolvidos. Segundo Mauri (1996) o processo de projeto torna-se uma construção contínua de um debate coletivo e interativo no qual cada ator pode fornecer a sua contribuição para elaborar demandas, perceber oportunidades, aprofundar posições comunicar, avaliar decisões e responsabilidades como respostas às incertezas.

No contexto audiovisual, a formulação de futuros possíveis torna a tomada de decisão um processo sólido e transparente, sem contudo perder a necessária criatividade que caracteriza este tipo de projeto. A deliberação por uma determinada alternativa é resultado da reunião, organização interpretação conjunta desta gama de dados do contexto. Enquanto um processo de conversação, os cenários estimulam o compartilhamento de informações fornecendo uma maior segurança ao trabalhar-se com inúmeras incertezas envolvidas em uma produção audiovisual.

Este artigo visou contribuir e estimular a reflexão sobre a potencialidade deste instrumento de design. 


\section{Referências}

UNITED NATIONS/UNPD/UNESCO. Creative Economy Report. Widening Local Development Pathways. New York: United Nations, 2013. Disponível em: http://www.unesco.org/culture/pdf/creative-economy-report2013.pdf. Acesso em: 18 nov. 2015.

HOWKINS, J. Economia Criativa: como ganhar dinheiro com ideias criativas. São Paulo: M. Books do Brasil, 2013.

AGÊNCIA NACIONAL DO CINEMA - ANCINE. Plano de diretrizes e metas para o audiovisual: o Brasil de todos os olhares para todas as telas. 1. Ed. Rio de Janeiro, 2013. Disponível em: <http://www.ancine.gov.br/sites/default/files/folhetos/PDM\%202013.pdf>. Acesso em:22 nov. 2015.

NESTA. Creating Growth: How the UK can develop world- class creative businesses. London, 2006.

DORST, K. Understanding design. Bis Publishers, Amsterdam, 2006.

LOCKWOOD, T. Transition: becoming a design-minded organization. In: T. Lockwood (Ed.). Design Thinking: Integrating Innovation, Costumer Experience, and Brand Value. New York: Allworth Press, 2010, p.81-95.

CROSS, N. Designerly ways of knowing. Springer: London, 2006.

MINTZBERG, $\mathrm{H}$. et al. The structure of unstructured decision processes. Administrative Science Quarterly. [S.I.], v. 21, n. 2, jun 1976, p. 246-275

REYES, P. Projeto por cenários: o território em foco. Porto Alegre: Sulina, 2015. 268p.

SIMON, H. A. A Capacidade de Decisão e de Liderança. Rio de Janeiro: Fundo de Cultura, 1972.

SIMON, H. A Making Management Decisions: the Role of Intuition and Emotion. Academy of Management Executive, v. 1, n. 1, feb. 1987, p. 57-64

SCHÖN, D.A. Educando o profissional reflexivo. 1. ed., Porto Alegre: Artmed, 2000.

ABRAMCZUK, A. A. A prática da tomada de decisão. São Paulo: Atlas, 2009.

BAZERMAN, M.H. Processo Decisório: para cursos de Administração, Economia e MBAs. Rio de Janeiro: Elsevier Editora, 2004.

MERONI, A. Strategic Design: Where we are now? Reflection around the foundations of a recent discipline. Strategic Design Research Journal, v. 1, n. 1, dec. 1, 2008, p. 31-38.

KAHNEMAN, D. Maps of bounded rationality: psychology for behaviral economics. The American Economic Review, v.93, n.5, p.1449-1475, 2003.

BUCHANAN, R. Wicked problems in design thinking. Design issues, v. 8, n. 2, 1992, p. 5-21.

SCHÖN, D.A. Educando o profissional reflexivo. 1. ed., Porto Alegre: Artmed, 2000.

CELASCHI, F. Dentro al progetto: appunti di merceologia contemporanea: In: CELASCHI, F.; DESERTI, A. Design e innovazione: strumenti e pratiche per la ricera applicada. Roma: Carocci Editore, 2007, p.15-38. 
DESERTI, A. Intorno al progetto: concretizzare l'innovazione. In: CELASCHI, F.; DESERTI, A. Design e innovazione: strumenti e pratiche per la ricerca applicata. Roma: Carocci Editore, 2007, p. 57-61. 